\title{
Collectif Argos: Climate Refugees
}

\author{
Singapore: The MIT Press 2010. ISBN 978-0-262-51439-2, Price \$ 29.95 US (paper). 349 pages
}

\author{
Hua Qin
}

Published online: 5 July 2011

(C) Springer Science+Business Media, LLC 2011

Environmental effects on human migration constitute an important area in the study of the relationship between population and the environment. In the past decade, there has been growing attention to the populations displaced by floods, storm surges, droughts, and other environmental hazards which will be exacerbated by climate change. Increased concerns about the impacts of global climate and environmental change on human mobility have fueled strong media and academic interest in climate induced migration. Climate Refugees stands out among the many publications on climate change and migration in recent years. ${ }^{1}$ With vivid photographs and well-written narratives, it presents a striking picture of human displacement and migration resulting from climate-related disasters.

The book includes nine cases of climate migrants which span the thematic and the geographic spectrums of the issue. Although much of the current discussion on climate induced migration tends to focus on sudden-onset disasters, the book also covers population mobility associated with slow-onset environmental changes. From devastating floods in Bangladesh to rising sea levels jeopardizing the island

\footnotetext{
${ }^{1} 2011$ marks the 60th anniversary of the 1951 Convention relating to the Status of Refugees and the 50th anniversary of the 1961 Convention on the Reduction of Statelessness. Two international conferences specifically on climate change and displacement were held this year: the Nansen Conference organized by the Norwegian Government (Oslo, Norway, June 5-7) and an expert roundtable organized by the United Nations High Commissioner for Refugees (Bellagio, Italy, February 22-25). In addition, the International Organization for Migration (IOM) held a workshop focusing on climate change, environmental degradation and migration in Geneva, Switzerland, March, 29-30.
}

\section{H. Qin $(\bowtie)$}

Climate Science and Applications Program,

National Center for Atmospheric Research,

PO Box 3000, Boulder, CO 80307, USA

e-mail: huaqin@ucar.edu nations of Tuvalu and Maldives and the Halligen of Germany, from violent hurricanes threatening the gulf coast of the United States to increasing desertification in Chad and China and permafrost and glacial melting in Alaska and Nepal, the Collectif Argos team has done an excellent job in exploring the human migration implications of global warming and related environmental changes.

The authors use the term "climate refugee" to challenge the restrictive definition of refugees adopted by the Geneva Convention of 1951. Nevertheless, by including a diverse body of migration cases, this book encompasses much wider dimensions of climate induced migration than its title conveys. Although similar terms, such as climate change refugees, climate migrants, climate change migration, and climate forced migration are often used interchangeably in the literature on climate change and migration, there are subtle differences among their definitions. The differentiation between climate refugees and migrants mirrors the debate on refugee-like and migrant-like environmental migration situations in general. Climate change induced voluntary migration and forced displacement can be viewed as the opposite ends of a continuum of possible mobility forms (Warner 2010). Climate refugee or displacement status indicates involuntary movement forced by climate change's detrimental effects. By contrast, climate or environmental migrants generally have at least some control over where and when to move to cope with climate change impacts. However, it is not always practical to draw a clear distinction between forced and voluntary motivation in climate induced migration.

The term "climate refugee" usually conjures up sad images of helpless displaced people with few alternatives for survival. The story of the New Orleans family described in this book suggests even involuntarily displaced people themselves are unwilling to be labeled as climate refugees, indicating that the more neutral term of "climate migrant" 
would be more useful to capture the wide range of climate change related migration and displacement. Based on the IOM's definition of environmental migrants, climate change migrants can be broadly defined as "persons or groups of people who, for compelling reasons of sudden or progressive changes in the environment as a result of climate change that adversely affect their lives or living conditions, are obliged to leave their habitual homes, or choose to do so, either temporarily or permanently, and who move either within their country or abroad" (Kniveton et al. 2008: 31).

There is no consensus on the potential scale of climate change induced migration across the world. The estimates and forecasts of people who could be displaced due to environmental effects resulting from climate change range widely from 200 million to 1 billion (Myers 2005; Christian Aid 2007). The key problem with the projection of climate change migration and displacement is the absence of a common and measurable definition of climate migrants. However, given the diversity of this migration process (e.g., forced or voluntary, temporary or permanent, internal or international), any attempt to precisely quantify the number of climate migrants would be a daunting challenge. Instead of presenting another aggregate estimate, the book offers a much more nuanced view of the various forms of climate induced migration by taking an empirically grounded approach to the issue.

Human migration can be conceptualized as one of the possible responses in a comprehensive framework of vulnerability to climate change (Romero Lankao and Qin 2011). The nine case studies included in this volume demonstrate that climate-related environmental changes may result in different migration streams. When acute climatic and environmental shocks rapidly destroy the whole livelihood base of a community, resettlement is often both the only and the last resort for the people affected. However, some other forms of climate induced migration, particularly seasonal or circular mobility, may be used as an adaptive strategy to slow-onset environmental changes such as droughts and land degradation.

The institutions and policies related to climate change induced migration are strongly shaped by the definition and perception of this issue. The authors of the book emphatically call for international cooperation and action to include climate refugees in existing legal frameworks for social or political refugees. However, simply expanding refugee protection to people displaced by climate hazards would not be sufficient to address the full complexity of the problem. A wide array of regional and national systems and strategies are needed to accommodate and support popula- tion mobility in the context of global climate and environmental change.

One other theme that is highlighted throughout the book is the rural-urban linkage in the interaction between climate change and environmental migration. Rural residents in many developing countries are particularly vulnerable to climate change due to their direct dependence on climatesensitive natural resources for basic livelihoods. Temporary and circular rural-urban labor migration is a popular income diversification strategy for rural households in the developing world. Climate-related environmental changes, such as farmland degradation and the decline of water supplies, can intensify rural migration to cities. On the other hand, cities can serve as major destinations for environmental migration inflows, as well as origin places of migration because of the increasing exposure to global climate change impacts (Adamo 2010). Thus, it is important to understand the climate change and migration issue in the broader settings of sustainable livelihoods, high mobility, and rapid urbanization.

To sum up, Climate Refugees is a timely effort to raise public awareness of the magnitude and urgency of climate change induced migration and displacement. While there remain great uncertainties about projected patterns of both climate change and associated migration, what we do know is that the mobility level of human populations will be even higher along with global climate and environmental change, and that this requires corresponding reforms in rules, strategies, and organizations at all levels of governance.

\section{References}

Adamo, S. B. (2010). Environmental migration and cities in the context of global environmental change. Current Opinion in Environmental Sustainability 2(3): 161-165.

Christian Aid (2007). Human tide: The real migration crisis. A Christian Aid report, May, available online at www.christianaid. org.uk/Images/human-tide.pdf.

Kniveton, D., Schmidt-Verkerk, K., Smith, C., and Black, R. (2008). Climate Change and Migration: Improving Methodologies to Estimate Flows. IOM Migration Research Series No. 33, Geneva.

Myers, N. (2005). Environmental refugees: An emerging security issue. Paper presented at the 13th Economic Forum, Prague, May 23-27, available online at www.osce.org/eea/14851.

Romero Lankao, P., and Qin, H. (2011). Conceptualizing urban vulnerability to global climate and environmental change. Current Opinion in Environmental Sustainability 3(3): 142-149.

Warner, K. (2010). Global environmental change and migration: Governance challenges. Global Environmental Change 20(3): 402-413. 